\title{
Tackling the climate targets set by the Paris Agreement (COP 21): Green leadership empowers public hospitals to overcome obstacles and challenges in a resource- constrained environment
}

E Weimann, ${ }^{1,2}$ MD, MMed (Paed), Endocrinology \& Metabolism, Habil, MPH;

B Patel, ${ }^{1}$ BSc, MB ChB, MFamMed, FCFP, FCPHM, MSc (Med Bioethics and Health Law)

${ }^{1}$ Groote Schuur Academic Hospital, Cape Town, South Africa

${ }^{2}$ Department of Information Systems, Faculty of Commerce, University of Cape Town, South Africa

Corresponding author: E Weimann (edda.weimann@westerncape.gov.za)

\begin{abstract}
The healthcare sector itself contributes to climate change, the creation of hazardous waste, use of toxic metals such as mercury, and water and air pollution. To mitigate the effect of healthcare provision on the deteriorating environment and avoid creating further challenges for already burdened health systems, Global Green Hospitals was formed as a global network. Groote Schuur Hospital (GSH), as the leading academic hospital in Africa, joined the network in 2014. Since then, several projects have been initiated to reduce the amount of general waste, energy consumption and food waste, and create an environmentally friendlier and more sustainable hospital in a resourceconstrained public healthcare setting. We outline the various efforts made to reduce the carbon footprint of GSH and reduce waste and hazardous substances such as mercury and polystyrene, and elaborate how obstacles and resistance to change were overcome. The hospital was able to halve the amount of coal and water used, increase recycling by $50 \%$ over 6 months, replace polystyrene cups and packaging with Forest Stewardship Council recyclable paper-based products, reduce the effect of food wastage by making use of local farmers, and implement measures to reduce the amount of expired pharmaceutical drugs. To improve commitment from all involved roleplayers, political leadership, supportive government policies and financial funding is mandatory, or public hospitals will be unable to tackle the exponentially increasing costs related to climate change and its effects on healthcare.
\end{abstract}

S Afr Med J 2017;107(1):34-38. DOI:10.7196/SAMJ.2017.v107i1.12023

On 22 April 2016, Earth Day, 177 nations gathered to sign the Paris Agreement (COP 21), and at the time of writing 187 countries have made their official commitment to take action on climate change. Minister Molewa signed the agreement on behalf of South Africa (SA). To reach the goals set out in this agreement will require a profound global effort. Each and every sector must step up to develop a low-carbon path for the future. The health sector plays a significant role, not only in taking action to reduce its own climate impacts, but also to act as a leader to inspire others to serve as role models.

As the Lancet Commission stated in 2009, climate change is 'the biggest public health threat of the 21 st century.'[1] Since then, the climate crisis has deepened severely, with higher frequency of extreme weather events and recurrences of El Niño. Scientific findings have become increasingly indisputable, intensifying the urgency for action. Climate change is already aggravating a wide range of health problems. As our planet warms, infectious diseases are spreading, threatening to reverse health improvements gained by great effort in many parts of the world. Heatwaves are growing in intensity and number, killing thousands of people and children, and aggravating chronic lung disease, heart disease and heatstroke. Increasingly severe storms, tornados, droughts and floods, as recently experienced in China, but also in SA, harm human health and put often overstretched and ill-prepared health systems at risk. If greenhouse gas emissions remain at the current level or even increase, climate change will have severe persistent and irreversible effects, undermining the food and water supply in many parts of the world, setting off mass migrations, and thereby triggering potentially unmanageable public health crises. Based on scientific evidence, we need to prevent atmospheric carbon dioxide concentrations exceeding 450 - 500 parts per million (ppm) to avoid the serious, often irreversible, damage to many natural systems and ecological processes that a global average temperature increase of 2 - $3^{\circ} \mathrm{C}$ would cause. ${ }^{[2]}$ Alarmingly, compared with $280 \mathrm{ppm}$ before industrialisation, a $400 \mathrm{ppm}$ target was already reached in both hemispheres earlier than expected, in June 2016. Radical action is therefore needed. While everyone will experience the hazards of climate change, the most vulnerable populations, especially in developing countries - the urban and rural poor - will endure the biggest impact.

Fossil fuel and coal are the greatest contributors to greenhouse gas emissions. The deterioration of air quality of large metropolitan areas in SA such as Johannesburg and Cape Town has become evident over the past decade. There has been very little research on climate change and its effect on health in SA, nor have policies been implemented to mitigate climate change and protect the population. The burning of wood and coal as well as uncontrolled air pollution from cars and trucks are major sources of significant local health problems such as airway diseases, chronic obstructive pulmonary disease and asthma. The use of fossil fuels makes a major contribution to air pollution, which, according to the World Health Organization (WHO), killed 7 million people globally in 2012 , causing twice as many deaths as AIDS, malaria and tuberculosis combined. ${ }^{[3]}$ 
To protect local and global health from climate change and its sources, the developed, together with developing, countries need to move towards an economy based on clean, renewable, healthy energy and significantly reduce the pollution of our environment. A transition to a clean-energy economy will benefit both the climate and public health. Healthcare providers such as hospitals, health systems and government health institutions can play a leadership role in this transition.

In SA, the National Department of Health approved a national climate change adaptation plan in $2014 .{ }^{[5]}$ This plan covers a general approach to climate change responses for the health sector. It does not offer a plan for implementation, but highlights the key areas of concern for the sector. In the SA Risk and Vulnerability Atlas, ${ }^{[6]}$ the identification of risks associated with climate change and the effects on health are addressed, inter alia. The government has also undertaken a set of in-depth analyses in a number of sectors, under the Long Term Adaptation Scenarios process, one of which was an analysis of the health sector. ${ }^{[7]}$ The effect of climate change on human health will be investigated through the analysis of a variety of complex interactions between changes in climate variables (temperature, heatwaves, rainfall) and health aspects. This will be examined by investigating influences on existing diseases via temperature spikes, vulnerable groups and psychological effects. However, the main focus is on building resilience, rather than mitigating the effect of climate change, through implementing and executing appropriate policies. Resilience in this context is defined as preparing for the effects of extreme weather and the shifting burden of disease.

Human health is likely to be affected, directly and indirectly, by increasing temperatures, more frequent heatwaves and changing rainfall patterns. A reduction in the availability of water, as well as in the supply of clean, potable water, may lead to reduced levels of personal hygiene and an increase in related diseases. Population growth, especially in metropolitan areas, coupled with a situation of less water, may lead to an increase in the incidence of water-borne diseases, further affected by deterioration in the quality of water sanitation. Higher temperatures will increase the quantity and spread of animal species such as rodents, some of which directly affect human health. The population's immune systems may be further compromised by extreme temperatures caused by climate change.

Temperatures are expected to rise and rainfall to decrease in all regions in Western Cape Province. Over the past 50 years, the Western Cape Province has seen the average temperature increase by more than $1^{\circ} \mathrm{C}$, resulting in more days over $32^{\circ} \mathrm{C}$ and even days over $36^{\circ} \mathrm{C} \cdot{ }^{[4]}$ Heat and heatwaves have an impact on human health, and in particular on people living in informal settlements. People exposed to heat and sunlight will be more prone to develop renal failure as a result of the high incident rate of hypertension in the SA population, ${ }^{[8]}$ an event that is also reported in other developing countries such as India. Vector- and food-borne diseases and temperature-related illnesses are likely to increase in the Western Cape in particular. Billions of litres of waste water, tons of plastic and other hazardous chemicals are dumped into the oceans, rivers and waterways every day, leading to disturbed ecosystems, affecting the food chain and augmenting the infection rate of bathers. ${ }^{[9,10]}$ The increased acidity of the oceans further aggravates climate change.

Climate change will have a severe socioeconomic impact and will probably decrease the already low life expectancy of South Africans further (currently 57 years). ${ }^{[11]}$ Some population groups are more vulnerable, especially the elderly, who are more prone to heat stress, as well as low-income communities and agricultural workers, who are more exposed to the sun and heat.

The SA health system is characterised by stark inequality between public and private healthcare providers, austerity measures, and shortages of hospital beds, transport facilities and skills. ${ }^{[12]}$ Every effort should therefore be made to minimise the effect of climate change ${ }^{[5]}$ and avoid further burdening the overstretched health system. Consequently, it is mandatory to implement and execute policies to boost renewable energies, to insulate buildings and healthcare facilities, and to reduce greenhouse gas emission, air, water and soil pollution, coal consumption and hazardous waste, ${ }^{[3]}$ as resilience can only be partly achieved and at very high costs.

\section{Goals and objectives of our Green Leadership projects}

\section{Reducing our own climate footprint}

Hospitals and healthcare providers are major energy consumers and can make a large contribution to the reduction in greenhouse gas emissions. Since 2014, Groote Schuur Hospital (GSH) in Cape Town, SA, has been a member of the Global Green and Healthy Hospitals Initiative (www.greenhospitals.net) that aims to lead the way towards low-carbon healthcare by reducing greenhouse gas and setting renewable energy targets. GSH's vision is to reduce its emissions, moving towards low-carbon and preferably carbonneutral healthcare. Considering the SA energy crisis, and the load shedding experienced over the last decade, we aim to deploy renewable energy, as this may be financially supported by the government ${ }^{[5]}$ and hospitals could receive additional funding for green energy solutions. We will further increase our energy efficiency measures, eliminate waste and leakages and when feasible deploy clean renewable energy to power our buildings. Currently, we are exploring the potential of solar thermal energy to address the heat requirements of the hospital, in collaboration with non-government organisations. Our progress is measured and reported on a monthly basis within the hospital and the Western Cape Province, and includes the financial savings related to these actions. We identify our practices that affect the climate, including purchasing and waste generation, and are currently also implementing plans to reduce the effects of these methods.

\section{Preparing for climate impact and creating resilience}

We need to be equipped to manage the health needs of our community, as well as be prepared for shifting disease patterns and an increasing incidence of extreme weather, creating resilience overall. To serve our communities, our hospital must remain operational during and after an extreme weather event. Hence, measures are required to ensure that our infrastructure, staff and communities are prepared for the immediate impact of extreme weather events and the longer-term impact of changing patterns of disease, as well as other climate impacts, combining these efforts with low-carbon solutions whenever possible. With regard to its lack of insulation, GSH itself is at present not adapted for the already-experienced rise in temperature and increased number of heatwaves.

\section{Leading the way to a low-carbon future in healthcare}

GSH, as a tertiary care facility and academic hospital, is committed to providing leadership for a healthy climate, backed up by our Healthcare Innovation Hub. To do so we educate healthcare professionals, students and hospital staff on the challenges and solutions relating to climate and health. In collaboration with the Provincial Climate and Health Committee we encourage public policy to move away from fossil fuel dependency and instead foster a healthy energy future, thereby protecting local health from climate change. As proposed by the Global Green Hospital Initiative, by moving towards low-carbon health systems, healthcare can mitigate its own climate impact, save money and lead by example. Consequently, we engage in green procurement 
methods, ${ }^{[13]}$ avoiding mercury content, and preferably acquire products produced locally or from neighbouring countries in southern Africa. Through providing societal leadership, ${ }^{[14]}$ we encourage a vision of a future with sustainable and green hospitals living with environmentally responsible communities on a healthy planet.

\section{The GSH Green Leadership projects}

To achieve the goals and objectives, we have embarked on various projects (Fig. 1) and have created a GSH green hospital leadership framework:

\section{Reducing the energy, coal and water consumption of the hospital}

This project is mainly driven by the engineering department. To keep up with the hospital 'steam demand' the boiler house was running two 8 -ton boilers at 6 tons of coal per hour in winter and 4.5 tons per hour in summer. Based on these extreme inefficiencies, a complete overhaul of the boiler house and steam reticulation was done. The hospital boiler house was built with 4 tons of coal-fired boilers in 1965 , which replaced the original steam generation system installed in the old hospital basement in the late 1930s. In the mid 1990s, three of the 4-ton boilers were replaced with two 8-ton coal-fired boilers and one of the 4-ton boilers remained. Over the years, the boilers became fouled with soot and fly ash, and the steam reticulation had a defective steam trapping system as well as many leaks. By understanding the design, repairing leaks and improving efficiencies, we reduced the coal consumption of the hospital by $48 \%$ between 2009 and 2015. There is an environmental benefit to using far less coal for the amount of steam required to ensure that the hospital operates efficiently and effectively. Not only do we now produce less carbon emissions, but as a result of the increased reticulation

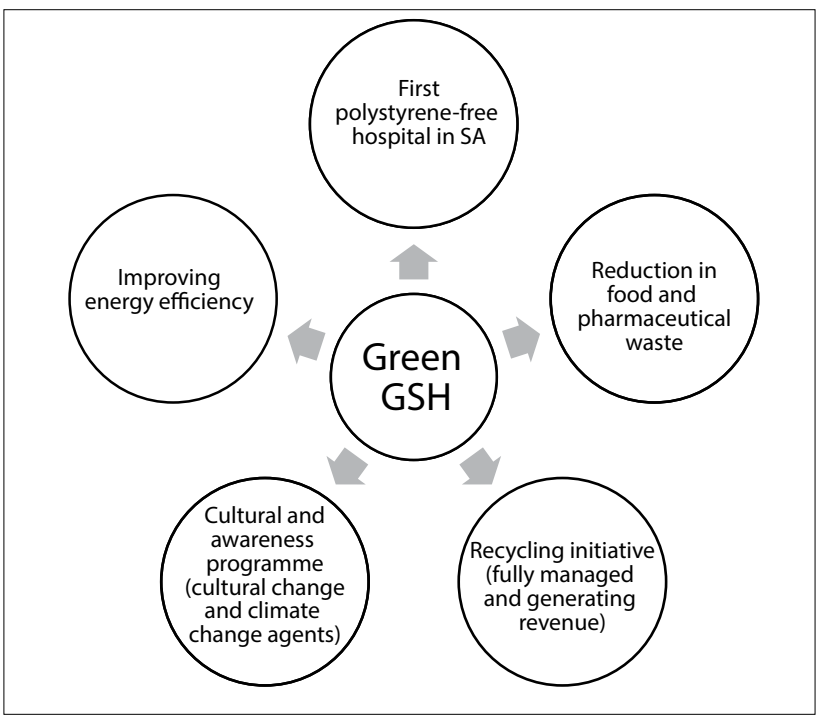

Fig. 1. GSH achievements to reduce the carbon footprint and environmental impact (GSH Green Leadership Framework). efficiency, we are also using less energy and water to produce steam and, as a result, using fewer water treatment chemicals. This also positively affects human health, as the physical load of the staff is reduced as well as the respiratory implications for people working in the surrounding neighbourhood. To minimise the effect of the remaining coal emission, we are currently applying for funding from the provincial government to install filters, to reduce the fine-particle pollution that is visible at GSH.

While the engineering department focused on reducing energy consumption and waste, management engaged in an awareness programme to promote the switching off of lights and appliances when not needed. Different presentations were given to encourage various departments and teams (e.g. students, doctors, nurses) to become agents tackling climate change. ${ }^{[11]}$ Appropriate signage to encourage energy-sensitive behaviour is displayed. The Western Cape provincial government has implemented a portal to monitor and visualise energy consumption (http://www.energyshop.co.za/WCDOH. html). The baseline consumption of GSH during the night remains elevated, despite awareness campaigns. We are now monitoring the energy consumption of the hospital on a daily basis via the governmental Smartmeter application. In addition, as outlined above, we aim to install filters to reduce the small-particle emission of the hospital.

GSH was able to save coal, water and electricity over the past 5 years and therefore we have significantly reduced our carbon footprint (Table 1).

\section{Introducing recycle bins and improvement in waste management}

Staff members from different areas of the hospital are continually trained in proper triaging and waste separation. In addition, presentations are given at staff meetings and the correct procedures are explained. Several departments have introduced recycling bins in their areas, including the management suites, GSH Healthcare Innovation Hub, the hospital facility board, and the Departments of Radiation Medicine and Medicine (Fig. 2). The University of Cape Town (UCT) Private Academic Hospital, which is located in the Groote Schuur building, has joined our effort by introducing recycling bins and adhering to improved waste management. Another effort is that departments install printers that print double-sided, to save paper. The total tonnage of recycled waste increased by $23 \%$ in 2015 and by $50 \%$ in the first 6 months of 2016; the total amount of recycling removed in 2015 was 144 tons, in contrast to 110.7 tons in 2014. In 2015, we generated ZAR106 174 from recycling alone.

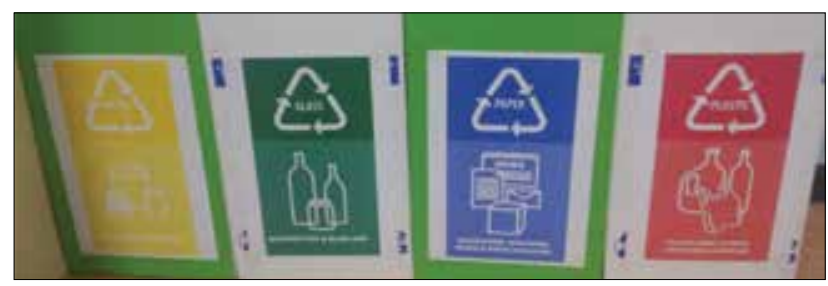

Fig. 2. Establishing recycling bins in the hospital.

Table 1. Reduction in water and coal consumption at GSH

\begin{tabular}{lllllll}
\hline & $\mathbf{2 0 1 1}$ & $\mathbf{2 0 1 2}$ & $\mathbf{2 0 1 3}$ & $\mathbf{2 0 1 4}$ & $\mathbf{2 0 1 5}$ & \% \\
\hline Coal (tons) & 3433 & 3469 & 3163 & 2214 & 1885 & -45.1 \\
Water (kL) & 652424 & 532088 & 503860 & 420782 & 371705 & -43.0 \\
Electricity (kW) & & 4256750 & 4256255 & 4269498 & 4016333 & -5.7 \\
Recycling (tons) & & & & 110.7 & 144.0 & +23.0
\end{tabular}


Additionally, food waste from the GSH kitchen is collected on a regular basis by a local farmer, for use as pig feed.

\section{Creating a polystyrene-free hospital}

Polystyrene is known as a major health and environmental hazard. It creates a major litter problem and is the fifth-largest creator of harmful waste worldwide. It is non-degradable and stays in the environment for hundreds of years, and toxic chemicals released by polystyrene are ingested, becoming part of marine life and the food chain. ${ }^{[15]}$ Polystyrene is suspected of causing cancer and leading to hormonal disturbances. ${ }^{[16]}$ In addition, polystyrene production contributes considerably to the depletion of the ozone layer. In spite of these well-established facts, polystyrene is still widely used in the environment by retailers and in the food processing industry, although alternative Forest Stewardship Council (FSC) paperbased products exist. At GSH, polystyrene cups and packaging were used for water dispensing and in the canteens. We engaged in finding suppliers who provide FSC-based paper cups and packaging. The UCT Private Academic Hospital also changed their procurement policy and introduced an FSC paper-based system. As the amount of paper that is recycled in SA is low, recycled paper needs to be imported from other countries. To achieve buy-in from the various roleplayers, meetings, discussions and presentations took place to provide the reasoning for replacing waste-intensive polystyrene packaging with biodegradable paper and gelatinebased bioplastic. This new strategy was rolled out in the hospital to reduce greenhouse gas emissions, and to limit the amount of waste and well-established health hazards created by the use of polystyrene cups. The hospital supply chain policy was therefore amended accordingly. As there was resistance to changing current habits, active change management processes were used. Finally, the canteens (outsourced to Feedem), GSH Private Academic Hospital (which belongs to the Netcare hospital group) and GSH hospital management agreed to dispense with polystyrene and use biodegradable paper packaging instead, enabling us to create the first polystyrene-free hospital in SA.

\section{Reducing the amount of pharmaceutical waste}

Pharmaceutical waste is a major problem, as it is toxic to the environment. Medicines prescribed unnecessarily in a resourceconstrained environment add to the quantity of waste. ${ }^{[17]}$ We are therefore working towards reducing polypharmacy and the amount of expired drugs. ${ }^{[17]}$ Currently, waste by medicine expiry is $<1 \%$ of total pharmaceutical procurement, although in a tertiary care facility this can amount to ZAR500 000 per year (Fig. 3). The GSH pharmacy has implemented measures to use or redistribute medicines before they expire, to reduce the amount of expired drugs and hence the waste. In addition, patients are asked, when they collect their prescribed medicines, what they do not need or still have in stock. Targets are set for the forthcoming year to use prescribed medicine more efficiently and economically.

\section{Discussion}

The GSH Green Hospital Leadership projects have demonstrated green leadership and environmental responsibility. We were able to engage staff from various levels of the hospital hierarchy to take ownership and drive the project in their areas. The effect and results are regularly disseminated throughout the hospital. In addition, the UCT Private Academic Hospital has joined our going-green projects, in particular by improving recycling and replacing polystyrene with FSC paper-based products. As we aim to engage staff members to work as a team to find solutions to existing problems, we implement

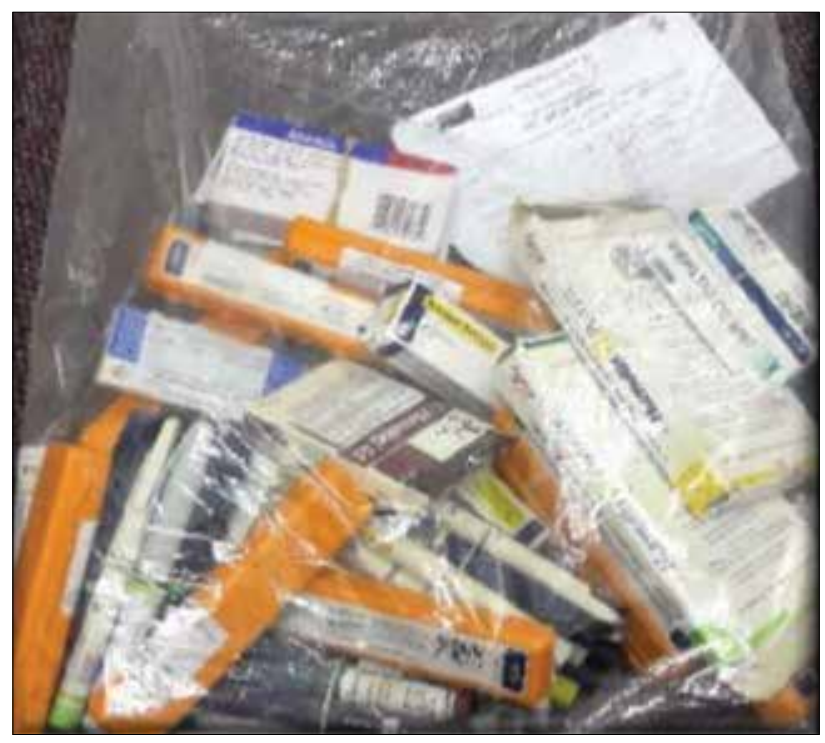

Fig. 3. Medicines returned after expiry date (wasteful expenditure).

sustainability with this approach as changes and new measures are taken up by the staff and are used in the everyday life of the hospital. In this way, a shift of mindset and thinking towards a culture of continuous improvement will occur. With the success of this project, we hope that the green leadership concept can be rolled out to other public healthcare facilities and schools in the country, and that combined green solutions can be initiated and implemented through the GSH Healthcare Innovation Hub, which the hospital created as a space where such creative thinking could be encouraged. This hub is the first of its kind in the public sector and several of the initiatives involving the changing of mindset and creation of awareness are happening there.

This project's innovation is addressing the daily challenges of reducing the carbon footprint, saving energy and minimising the amount of hazardous waste in a public hospital by generating profits through our actions. Our data clearly show that the Green Hospital projects are sustainable and revenues are growing. The successful project rollout has created enthusiasm among the staff to act as climate change agents and environmental activists and has generated innovative solutions from within. The teams working on the projects had a sense of ownership over and pride in the accomplishments and in the difference made towards achieving an environmentally friendly and greener hospital. Additionally, the projects were designed in such a way that the innovations can be rolled out in other health facilities.

The Green Hospital projects could prosper from the support of governmental funding. Some countries (e.g. the USA, the UK, European countries) provide governmental support and therefore enhance green leadership initiatives. Healthcare facilities could become more energy independent by installing green energy solutions such as solar, thermal and wind energy. In addition, the carbon and waste footprint of each healthcare facility could be calculated and advertised on a regular basis to encourage competition between facilities. By creating a governmental green healthcare platform, different green teams would be able to crosspollinate and inspire each other.

Acknowledgements. R de Jager is in charge of waste management at GSH and we acknowledge his engagement in the Green Leadership projects. D Smith, head of the engineering department at GSH, kindly provided 
input on water, energy and coal consumption. V Naicker, head of the pharmacy, drives the project to reduce pharmaceutical waste. We commend the support for polystyrene-free canteens received by S Esterhuizen and her team from Feedem at GSH. L Shield, executive hospital manager at Netcare UCT Private Academic Hospital, joined our green projects and implemented a polystyrene-free policy, recycling bins and improved waste management at the hospital facility. We appreciate her commitment. We recognise the input of the Western Cape Provincial Climate and Health Committee and the Global Green and Healthy Hospitals Initiative.

1. Haines A. Climate Change and Health. Am J Prev Med 2008;35(Sept):1-5. http://dx.doi.org/10.1016/j. amepre.2008.08.003

2. McMichael AJ, Friel S, Nyong A, Corvalan C. Global environmental change and health: Impacts, inequalities, and the health sector. BMJ 2008;336(7637):191-194. http://dx.doi.org/10.1136/bmj.39392.473727.AD

3. Watts N, Adger WN, Agnolucci P, et al. Health and climate change: Policy responses to protect public . Watts N, Adger WN, Agnolucci P, et al. Health and climate change: Policy responses to protect
health. Lancet 2015;386(10006):1861-1914. http://dx.doi.org/10.1016/S0140-6736(15)60854-6

4. Costello A, Mustafa Abbas M, Allen A, et al. Managing the health effects of climate change. Lancet 2009;373(9672):1659-1733. http://dx.doi.org/10.1016/S0140-6736(09)60935-1

5. Government of the Republic of South Africa.The South African Climate Change Response Strategy. 2001. http://www.climateresponse.co.za/home/gp/1 (accessed 19 November 2016).

6. Department of Science and Technology, South Africa. South African Risk and Vulnerabilty Atlas. http://sarva.dirisa.org/ (accessed 19 November 2016).

7. Department of Environmental Affairs, South Africa. Long Term Adapation Scenarios (LTAS). https:// www.environment.gov.za/longterm_adaptationscenarios (accessed 19 November 2016).
8. Kearney PM, Whelton M, Reynolds K, Muntner P, Whelton PK, He J. Global burden of hypertension: Analysis of worldwide data. Lancet 2005;365(9455):217-223. http://dx.doi.org/10.1016/S01406736(05)17741-1

9. Weimann E. Blue Flag beaches - bathers at risk for thalassogenic diseases. J Environ Ecol 2014:5(1):3845. http://dx.doi.org/10.5296/jee.v5i1.5773

10. Weimann E. Improved waste water treatment could create jobs and reduce health care costs. Cape Times 9 January 2015. https://www.pressreader.com/south-africa/cape-times/20150109/281809987272483 (accessed 27 August 2016)

11. World Bank. Data. South Africa. 2016. http://data.wordbank.org/country/south-africa (accessed 17 June 2016)

12. Weimann E, Stuttaford MC. Consumers' perspectives on National Health Insurance in South Africa: Using a mobile health approach. JMIR mHealth uHealth. 2014;2(4):1-14. http://dx.doi.org/10.2196/ mhealth. 3533

13. Western Cape Provincial Government. Guideline on greening procurement of goods or services in the Western Cape Government. 2013. http://www.sa-tenders.co.za/content/green-procurement-policyguidelines-part-sustainable-public-procurement-delivery-state (accessed 24 June 2016).

14. Duvivier RJ, Watts NR, Rukavina, S, Kaduru C. Doctors talk climate change - students take action Lancet 2011;377(9770):995. http://dx.doi.org/10.1016/S0140-6736(11)60384-X

15. Koelmans AA, Besseling E, Shim WJ. Marine anthropogenic litter. 2015. http://dx.doi.org/10.1007/9783-319-16510-3

16. Yang CZ, Yaniger SI, Jordan VC, Klein DJ, Bittner GD. Most plastic products release estrogenic chemicals: A potential health problem that can be solved. Environ Health Perspect 2011;119(7):989996. http://dx.doi.org/10.1289/ehp.100322

17. Kreisberg J, Zheng C. Managing unused pharmaceuticals in a hospice setting: A pilot study. Am J Hosp Palliat Care 2011;28(8):536-538. http://dx.doi.org/10.1177/1049909111405788

Accepted 3 October 2016 